\title{
Erratum to: Anticipated Negative Police-Youth Encounters and Depressive Symptoms among Pregnant African American Women: A Brief Report
}

\author{
Fleda Mask Jackson • Sherman A. James • \\ Tracy Curry Owens • Alpha F. Bryan
}

Published online: 11 April 2017

(C) The New York Academy of Medicine 2017

\section{Erratum to: J Urban Health \\ DOI 10.1007/s11524-017-0136-3}

Please note that the surname of the last author of this article, Alpha F. Bryan, was misspelled in this article as originally published (it was spelled "Bryant" rather than "Bryan").

The online version of the original article can be found at http://dx. doi.org/10.1007/s11524-017-0136-3

F. M. Jackson $(\bowtie)$

Department of Psychology, Spelman College, Atlanta, GA, USA e-mail: fledamjackson@gmail.com

S. A. James

Epidemiology Department, Rollins School of Public Health,

Emory University, Atlanta, GA, USA

T. C. Owens

Department of Psychology, Morehouse College, Atlanta, GA, USA

A. F. Bryan

Clayton County Board of Health, Jonesboro, GA, USA

Present Address:

F. M. Jackson

Save 100 Babies, Atlanta, GA, USA 